\title{
Chemical composition, antioxidant and anticancer activity of licorice from Fruska Gora locality
}

\author{
Sanja Vlaisavljevića,*, Filip Šibul ${ }^{\mathrm{a}}$, Izabella Sinka ${ }^{\mathrm{b}}$, Istvan Zupko ${ }^{\mathrm{b}, \mathrm{c}}$, Imre Ocsovszki $^{\mathrm{d}}$, \\ Suzana Jovanović-Šanta ${ }^{a}$ \\ ${ }^{a}$ University of Novi Sad Faculty of Sciences, Department of Chemistry, Biochemistry and Environmental Protection, Trg Dositeja Obradovića 3, Novi Sad, Serbia \\ ${ }^{\mathrm{b}}$ Department of Pharmacodynamics and Biopharmacy, University of Szeged, Eötvös u. 6, Szeged, Hungary \\ ${ }^{c}$ Interdisciplinary Centre for Natural Products, University of Szeged, Eötvös u. 6, Szeged, Hungary \\ ${ }^{\mathrm{d}}$ Department of Biochemistry, University of Szeged, Dóm tér 9, Szeged, Hungary
}

\section{A R T I C L E I N F O}

\section{Keywords:}

Licorice

Bioactive compounds

Antioxidant potential

Anticancer activity

\begin{abstract}
A B S T R A C T
The present study was undertaken in order to evaluate the potential application of fresh and dry roots and leaves ethylacetate extracts of licorice from locality of Fruska Gora (Serbia) as a new source of valuable bioactive compounds with health benefits. Forty bioactive compounds have been quantified using LC-MS-MS and remarkable differences have been found among the extracts. The most abundant compounds were observed in the extract of fresh root. Therefore, this extract showed the strongest antioxidant potential and was the most effective that induced noticeable necrosis on breast MDA-MB-361 adenocarcinoma cell line and exhibited considerable proapoptotic property on SiHa ovarian cancer cell line. All presented results indicate fresh root of tested plant could have pharmacological potential, especially as a valuable source of natural antioxidants and/or phytoestrogens, which could indicate its long term use in prevention and/or therapy of oxidative stress-related diseases including some types of cancer.
\end{abstract}

\section{Introduction}

Licorice (Glycyrrhiza glabra L.) is spread on a wide part of Northwest Europe, North Africa, Siberia and the Caucasus, as well as in Asia. In Serbia, it is rarely found. Fruska Gora mountain, Cortanovci forest $\left(45^{\circ}\right.$ $9^{\prime} 16^{\prime \prime}$ North, $20^{\circ} 1^{\prime} 14$ " East) was locality where plant material was harvested for present study. Licorice is one of the medicinal plants known and used for centuries. Ancient people used licorice as a healing agent, but also for flavoring drinks. Roots and leaves of G. glabra contain a wide spectrum of bioactive constituents such as triterpenes (glycyrrhetic acid, glycyrrhizin), phenols (including liquiritigenin, liquiritin, isoliquiritigenin, isoliquiritin) and many others, detected by different chromatography techniques (Biondi et al., 2005; Jiang et al., 2013; Liao et al., 2012a,b; Siracusa et al., 2011; Wang et al., 2015; Wang and Yang, 2007; Zadeh and Kor, 2013), which are most likely responsible for therapeutic properties mentioned below.
Many reports presented antioxidant (Dong et al., 2014; Gupta et al., 2008; Martins et al., 2015; Parvaiz et al., 2014; Visavadiya and Narasimhacharya, 2006), antimicrobial (Gupta et al., 2008; Saraf et al., 2013; Sultana et al., 2010) activity - mainly reflected through antiHelicobacter pylori (Asha et al., 2013; Fukai et al., 2003), antiviral (Cheel et al., 2010; Wang et al., 2015), antiinflamatory (Biondi et al., 2005; Farag et al., 2015; Zheng et al., 2014). as well as antiproliferative activity (Basar et al., 2015; Chin et al., 2007; Dunlap et al., 2015; Farag et al., 2015; Huang et al., 2014; Yan et al., 2014) related to the content of bioactive compounds from G. glabra. Standardized licorice extract is used in sweets, tobacco industry and cosmetics, as well as an additive to different beverages (liqueur, brandy, etc.) because of its sweet taste (Chin et al., 2007). Many phenols present in licorice extracts such as liquiritigenin, liquiritin, isoliquiritigenin, isoliquiritin, glabridin, formononetin are responsible for phytoestrogen activity of this plant extracts (Tang et al., 2015). They can selectively bind to peroxisome

\footnotetext{
Abbreviations: AAE, ascorbic acid equivalents; BHA, butylated hydroxyanisole; BHT, butylated hydroxytoluene; DPPH, 2,2 diphenyl-1-picrylhydrazyl; dw, dry weight; EDTA, ethyle-

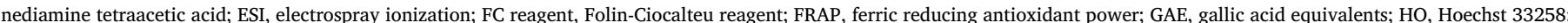

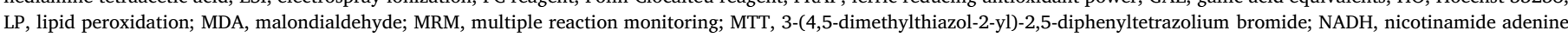

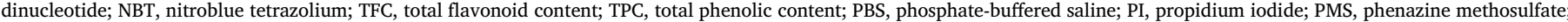
$\mathrm{QE}$, quercetin equivalents; SRB, sulforhodamine B; TBA, 2-thiobarbituric acid; TPTZ, 2,4,6-tripyridil-s-triazine

* Corresponding author at: Department of Chemistry, Biochemistry and Environmental Protection, Faculty of Sciences, University of Novi Sad Trg Dositeja Obradovića 3, 21000 Novi Sad, Serbia.

E-mail address: sanja.vlaisavljevic@dh.uns.ac.rs (S. Vlaisavljević).
} 
proliferator-activated receptor gamma or estrogen receptor, causing lipid reduction and having some good effects on hormone imbalances or menopausal symptoms in women. Hence, licorice is also used in hormone replacement therapy (Boonmuen et al., 2016; Simmler et al., 2013). Although the research attention is focused mostly on the healing properties of roots, the leaves should not be neglected, because they also contain bioactive substances such as flavonoids (naringein, astragalin, isoquercetrin, vicenin, etc.) (Biondi et al., 2005; Siracusa et al., 2011).

Until now, there were no reports on study of phytochemical properties of the licorice extracts and connection with their biological activity, from any localities. We performed such a study of licorice from Fruska Gora mountain. Thus, this could be a valuable study and contribution to the use in human nutrition and also in the prevention and treatment of many diseases of this rarely - found plant. The present study was undertaken to characterize and quantify selected bioactive compounds in extracts of G. glabra L. leaves and root and evaluate their antioxidant and anticancer potential.

\section{Material and methods}

The plant material (root and leaves) was collected during spring 2014 on Fruska Gora (Cortanovaci forest), Vojvodina, Serbia. The plant was determinate by Dr. Sanja Vasiljevic and a voucher specimen of the plant was confirmed and deposited at Herbarium of Department of Applied Botany, at Faculty of Agriculture; University of Belgrade. The samples are abbreviated as L1-fresh root, L2- dry root; L3- fresh leaves; L4-dry leaves.

The extracts were prepared by Microwave-assisted (MW) extraction. The method was used before for isolation of phenolic compounds. Using microwaves instead of steam, the interaction of electromagnetic fields with the liquid present in the cell vacuoles leads to their cracking and rapid exit of the contents (Flamini et al., 2007). This method has a few advantages over conventional extraction: the extraction time is shorter and the process is less expensive.

Previously chopped dried and fresh plant material $(5 \mathrm{~g})$ was placed in the flask $(100 \mathrm{~mL})$ and coated with $50 \mathrm{~mL}$ of $70 \%$ ethyl acetate. The extraction lasted $10 \mathrm{~min}$. After the filtration the solvent evaporated in vacuo at $45^{\circ} \mathrm{C}$. Dried extracts were dissolved in $80 \%$ ethanol $(\mathrm{v} / \mathrm{v})$ to obtain $100 \mathrm{mg} / \mathrm{mL}$ (stock solution). Extraction was performed using modified, previously described MW assistant extraction (Vlaisavljevic et al., 2016).

\subsection{Quantitative LC-MS/MS analysis of the selected bioactive compounds}

New method for quantification of 17 bioactive compounds was hereby developed. The optimized compound-specific parameters for quantification of 17 compounds in dynamic MRM (MRM (multiple reactions monitoring) mode - retention time, precursor ion, product ion, voltage of fragmentor, collision voltage) are given in Table 1.

Further, the method for quantification of 45 plant phenolics (Orčić et al., 2014) was used for quantitative determination of phenolic compounds in the G. glabra extracts. Prior to the analysis, all extracts were diluted in a mixture of water and methanol premixed in 1:1 ratio, to obtain a final concentration of $2 \mathrm{mg} / \mathrm{mL}$. For both mixes of 45 and 17 compounds, fifteen working standards, ranging from $1.53 \mathrm{ng} / \mathrm{mL}$ to $25.0 \times 10^{3} \mathrm{ng} / \mathrm{mL}$, were prepared by serial 1:1 dilutions of standard water-methanol mixture (1:1). All samples and standards were analyzed using Agilent Technologies (AT) 1200 Series high-performance liquid chromatography coupled with AT 6410A Triple Quad tandem mass spectrometer with electrospray ion source, and controlled by AT MassHunter Workstation software - Data Acquisition (ver. B.03.01). Into the system $5 \mu \mathrm{L}$ of the samples/standards were injected, and compounds were separated on Zorbax Eclipse XDB-C18 $(50 \mathrm{~mm} \times 4.6 \mathrm{~mm}$, $1.8 \mu \mathrm{m}$ ) rapid resolution column held at $50{ }^{\circ} \mathrm{C}$. Mobile phase consisted of A: $0.05 \%$ aqueous formic acid and B: methanol, was delivered at flow
Table 1

Optimized dynamic MRM parameters for 17 compounds.

\begin{tabular}{llllll}
\hline Compound & $\begin{array}{l}\text { Precursor } \\
m / z\end{array}$ & $\begin{array}{l}\text { Product } \\
m / z\end{array}$ & $\begin{array}{l}V_{\text {fragmentor }} \\
(\mathrm{V})\end{array}$ & $\begin{array}{l}V_{\text {collision }} \\
(\mathrm{V})\end{array}$ & $\begin{array}{l}t_{R} \\
(\mathrm{~min})\end{array}$ \\
\hline Equol & 241 & 119 & 110 & 25 & 3.72 \\
Daidzein & 253 & 208 & 145 & 30 & 3.43 \\
Liquiritigenin & 255 & 119 & 100 & 20 & 3.33 \\
Isoliquiritigenin & 255 & 119 & 100 & 20 & 4.89 \\
Formononetin & 267 & 252 & 100 & 15 & 5.49 \\
Genistein & 269 & 133 & 145 & 30 & 1.72 \\
Glycitein & 283 & 268 & 140 & 15 & 3.55 \\
Calycosin & 283 & 268 & 140 & 15 & 3.74 \\
Biochanin A & 283 & 268 & 140 & 20 & 5.98 \\
Enterolactone & 297 & 253 & 160 & 20 & 3.8 \\
Enterodiol & 301 & 253 & 140 & 20 & 3.5 \\
Pinoresinol & 357 & 151 & 140 & 15 & 3.33 \\
Daidzin & 415 & 253 & 200 & 15 & 1.3 \\
Genistin & 431 & 269 & 180 & 15 & 1.72 \\
Glycitin & 445 & 282 & 200 & 25 & 1.41 \\
Glycyrrhetinic acid & 469 & 425 & 280 & 40 & 8.93 \\
Glycyrrhizin & 821 & 351 & 220 & 40 & 7.41 \\
\hline
\end{tabular}

rate of $1 \mathrm{~mL} / \mathrm{min}$ in gradient mode $(0 \mathrm{~min} 30 \% \mathrm{~B}, 6 \mathrm{~min} 70 \% \mathrm{~B}, 9 \mathrm{~min}$ $100 \%$ B, $12 \mathrm{~min} 100 \% \mathrm{~B}$, re-equilibration time $3 \mathrm{~min}$ ). Eluted compounds were detected by ESI-MS, using the ion source parameters as follows: nebulization gas $\left(\mathrm{N}_{2}\right)$ pressure 50 psi, drying gas $\left(\mathrm{N}_{2}\right)$ flow $10 \mathrm{~L} / \mathrm{min}$ and temperature $350^{\circ} \mathrm{C}$, capillary voltage $4 \mathrm{kV}$, in negative polarity (negative ionization mode, NI). Data were acquired in dynamic MRM mode, using the optimized compound-specific parameters (Orčić et al., 2014). For all the compounds, peak areas were determined using Agilent MassHunter Workstation software - Qualitative Analysis (ver. B.03.01.). Calibration curves were plotted and samples' concentrations calculated using the OriginLabs Origin Pro (ver. 9.0) software.

\subsection{Determination of the total bioactive components}

The total Phenol Content (TFC) was performed using the method described previously customized for 96-well microplates (Fukumoto and Mazza, 2000). The aluminum chloride colorimetric method (Jia et al., 1999), adapted for 96-well plates, was used to determine the total content flavonoids content (TFC).

The total phenol content was expressed as milligrams of gallic acid equivalents (GAE) per gram of dry weight (dw) of extract, calculated according to the standard calibration curve.The mean values of flavonoid content were expressed as milligrams of quercetin equivalents (QE) per gram of dry weight (dw) of extract, calculated according to the standard calibration curve.

\subsection{DPPH assay}

Plant extracts were tested for the scavenging effect on the DPPH radical (Sánchez-Moreno et al., 1999). The percentage of inhibition I (\%) for each radical species was calculated using the following equation: $I(\%)=100 \times\left(A_{\text {blank }}-A_{\text {sample }}\right) / A_{\text {blank }}$, where $A_{\text {blank }}$ was the absorbance of the control reaction and $A_{\text {sample }}$ was the absorbance of the examined samples, corrected for the value of the blank probe. From the obtained I (\%) values, the $\mathrm{IC}_{50}$ values (which represented the concentrations of the examined extracts that caused $50 \%$ neutralization) were determined by linear regression analysis, using Origin software, version 9.0.

\subsection{Hydroxyl-radical (HO•) scavenger capacity}

Scavenging capacity for HO radical of the G. glabra leaves and root extracts was determined by monitoring the chemical degradation of 2deoxy-D-ribose (Cheesman et al., 1998). The percentage of inhibition I (\%) for each radical species was calculated using the following 
equation: $\mathrm{I}(\%)=100 \times\left(\mathrm{A}_{\text {blank }}-\mathrm{A}_{\text {sample }}\right) / \mathrm{A}_{\text {blank }}$, where $\mathrm{A}_{\text {blank }}$ was the absorbance of the control reaction and $A_{\text {sample }}$ was the absorbance of the examined samples, corrected for the value of the blank probe. From the obtained I (\%) values, the $\mathrm{IC}_{50}$ values (which represented the concentrations of the examined extracts that caused $50 \%$ neutralization) were determined by linear regression analysis, using Origin software, version 9.0.

\subsection{Superoxide anion $\left(\mathrm{O}_{2} \cdot{ }^{-}\right)$scavenger capacity}

The capability of extracts to neutralize superoxide anion formed by the reduction of nitroblue tetrazolium (NBT) with NADH mediated by phenazine methosulfate (PMS) under aerobic conditions was conducted according to Cos et al. (1998). The percentage of inhibition I (\%) for each radical species was calculated using the following equation: I (\%) $=100 \times\left(A_{\text {blank }}-A_{\text {sample }}\right) / A_{\text {blank }}$, where $A_{\text {blank }}$ was the absorbance of the control reaction and $A_{\text {sample }}$ was the absorbance of the examined samples, corrected for the value of the blank probe. From the obtained I (\%) values, the $\mathrm{IC}_{50}$ values (which represented the concentrations of the examined extracts that caused $50 \%$ neutralization) were determined by linear regression analysis, using Origin software, version 9.0.

\subsection{NO scavenger capacity}

Test of nitric oxide radical (NO $\cdot$ ) scavenging capacity was based on method of Green et al. (1982), adapted for 96-well plates. The percentage of inhibition I (\%) for each radical species was calculated using the following equation: I $(\%)=100 \times\left(\mathrm{A}_{\text {blank }}-\mathrm{A}\right.$ sample $) / \mathrm{A}_{\text {blank }}$, where $A_{\text {blank }}$ was the absorbance of the control reaction and $A_{\text {sample }}$ was the absorbance of the examined samples, corrected for the value of the blank probe. From the obtained I (\%) values, the $\mathrm{IC}_{50}$ values (which represented the concentrations of the examined extracts that caused $50 \%$ neutralization) were determined by linear regression analysis, using Origin software, version 9.0.

\subsection{Reducing power - FRAP assay}

To evaluate the reducing power of extracts, the ferric ion reducing antioxidant power (FRAP) assay (Benzie and Strain, 1996), modified for 96-well plates, was undertaken. Mean values of reducing power were expressed as milligrams of ascorbic acid equivalents (AAE) per gram of dry weight of extract calculated according to the standard calibration curve.

\subsection{Statistical analysis}

All of the results were expressed as mean \pm SD of three different trials. A comparison of the group means and the significance between the groups were verified by one-way ANOVA. Statistical significance was set at $\mathrm{p}<0.05$.

\subsection{Cell culturing}

Human breast cancer cell lines (MCF7, T47D, MDA-MB-231 and MDA-MB-361), a cervical cancer cell line (HeLa) and an ovarian cancer cell line (A2780) were purchased from ECACC (European Collection of Cell Cultures, Salisbury, UK), while SiHa cells (cervical cancer) were obtained from ATCC (American Tissue Culture Collection, Manassas, Virginia, USA). Cells were cultivated in minimal essential medium supplemented with $10 \%$ fetal bovine serum, $1 \%$ nonessential amino acids and an antibiotic-antimycotic mixture. All media and supplements were obtained from Lonza Group Ltd. (Basel, Switzerland). The cells were maintained at $37^{\circ} \mathrm{C}$ in humidified atmosphere containing $5 \% \mathrm{CO}_{2}$.

\subsection{Antiproliferative activity measured by MTT assay}

The growth-inhibitory activity of the extracts was determined by MTT method against a panel of human cancer cell lines of gynecological origin (Mosmann, 1983). Briefly, all types of used cells were seeded into 96-well plates at a density of 5000 cells/well, with exception for MDAMB-361 cells, which were seeded at 10000/well. After an overnight preincubation cells were incubated with the tested extracts at 10 and $30 \mu \mathrm{g} / \mathrm{mL}$. After incubation for $72 \mathrm{~h}, 5 \mathrm{mg} / \mathrm{mL}$ MTT solution was added and the samples were incubated for another $4 \mathrm{~h}$. The precipitated formazan crystals were dissolved in dimethyl sulfoxide (DMSO) and the absorbance was measured at $545 \mathrm{~nm}$ with a microplate reader. Stock solutions of the extracts were prepared with DMSO $(10 \mathrm{mg} / \mathrm{mL})$ and the highest concentration of the solvent $(0.3 \%)$ has no substantial action on the cell viability. Two independent experiments with 5 wells in each condition were performed.

\subsection{Hoechst 33258-propidium iodide double staining}

On the basis of the results of MTT, SiHa and MDA-MB-361 cell lines were selected for treatment with licorice fresh root extract L1. Nearconfluent SiHa or MDA-MB-361 cells were seeded into a 96-well plate (5000 cells/well). After incubation for $24 \mathrm{~h}$ with the tested extract, Hoechst 33258 (HO) and propidium iodide (PI) were added to the culture medium to give final concentrations of 5 and $3 \mu \mathrm{g} / \mathrm{mL}$, respectively. The cells were incubated with the staining mixture for $1 \mathrm{~h}$ at $37^{\circ} \mathrm{C}$ and were then photographed by means of a Nikon Eclipse microscope equipped with an epifluorescence attachment containing the appropriate optical blocks and a QCapture CCD camera. The staining allowed the identification of live, early-apoptotic, late-apoptotic/necrotic cells. Hoechst 33258 permeates all the cells and makes the nuclei appear blue. Apoptosis was revealed by nuclear changes such as chromatin condensation and nuclear fragmentation. The necrotic and the late-apoptotic cells were identified as cells with propidium iodide uptake, which indicates loss of membrane integrity, leading the cell nuclei being stained red (Ribble et al., 2005).

\subsection{Analysis of cell cycle by flow cytometry}

On the basis of the results of MTT and the double staining assays, the cell cycle phase distribution of SiHa cells treated with extract L1 was determined by flow cytometry. Cells were seeded into 6-well plates at a density of 300000 cells/well. After $24 \mathrm{~h}$ of treatment the cells were washed twice with cold phosphate-buffered saline (PBS), harvested by trypsinization and centrifuged at $1500 \mathrm{rpm}$ for $10 \mathrm{~min}$. After washing in PBS, the cells were fixed in $1 \mathrm{~mL}$ cold $70 \%$ ethanol for $30 \mathrm{~min}$. Samples were stained with $1.0 \mathrm{~mL}$ dye solution containing $0.02 \mathrm{mg} / \mathrm{mL}$ RNAse A, $0.1 \mathrm{mg} / \mathrm{mL}$ PI, $0.003 \mathrm{ml} / \mathrm{ml}$ Triton-X and $1.0 \mathrm{mg} / \mathrm{mL}$ sodium citrate in distilled water, and the mixture was incubated in the dark for $60 \mathrm{~min}$ at room temperature. Cells were analyzed by a Partec CyFlow instrument (Partec GmbH, Münster, Germany). In each analysis, 20000 events were recorded, and the percentages of the cells in the different cell cycle phases (subG1, G1, S and G2/M) were determined using ModFit Software. The subG1 fraction was regarded as the apoptotic cell population (Vermes et al., 2000).

Statistical analyses were performed by GraphPad Prism 5 (GraphPad Software, San Diego, CA, USA) using ANOVA followed by Newman-Keuls Comparison Test.

\section{Results and discussion}

3.1. LC-MS-MS analysis: quantitative determination of bioactive compounds in $G$. glabra extracts

Earlier reports on the bioactive compounds content in extracts of $G$. glabra from different localities are based on narrow spectrum of phenols 
Table 2

LC-MS-MS quantification of bioactive compounds presented in G. glabra extracts ( $\mu \mathrm{g} / \mathrm{g} \mathrm{dw}$ ).

\begin{tabular}{|c|c|c|c|c|c|}
\hline & Compounds & L1 & L2 & L3 & L4 \\
\hline \multirow[t]{15}{*}{ Phenolic acids } & p-Hydroxybenzoic acid & $52.89 \pm 0.01^{\mathrm{d}}$ & $17.93 \pm 0.01^{\mathrm{c}}$ & $8.51 \pm 0.025^{\mathrm{b}}$ & $6.02 \pm 0.06^{\mathrm{a} \S}$ \\
\hline & Protocatechuic acid & $2.81 \pm 0.07^{\mathrm{d}}$ & $2.06 \pm 0.07^{\mathrm{c}}$ & $1.13 \pm 0.03^{\mathrm{b}}$ & $0.38 \pm 0.10^{\mathrm{a}}$ \\
\hline & 2.5-Dihydroxybenzoic acid & $1.61 \pm 0.11^{\mathrm{b}}$ & $0.35 \pm 0.02^{\mathrm{a}}$ & $3.20 \pm 0.01^{\mathrm{c}}$ & $1.98 \pm 0.32^{\mathrm{b}}$ \\
\hline & p-Coumaric acid & $73.82 \pm 1.31^{\mathrm{d}}$ & $20.56 \pm 1.02^{c}$ & $19.53 \pm 0.02^{b}$ & $9.79 \pm 0.01^{\mathrm{a}}$ \\
\hline & Vanillic acid & $9.40 \pm 0.05^{\mathrm{c}}$ & $5.08 \pm 0.04^{\mathrm{b}}$ & $4.30 \pm 0.1^{\mathrm{a}}$ & n.d. \\
\hline & Gallic acid & $5.41 \pm 0.19^{\mathrm{a}}$ & $4.97 \pm 0.06^{\mathrm{b}}$ & $4.55 \pm 0.05^{\mathrm{b}}$ & $4.15 \pm 0.08^{b}$ \\
\hline & Caffeic acid & $1.20 \pm 0.06^{\mathrm{c}}$ & $1.18 \pm 0.07^{\mathrm{c}}$ & $0.77 \pm 0.03^{b}$ & $0.55 \pm 0.03^{\mathrm{a}}$ \\
\hline & Quinic acid & $730.89 \pm 0.33^{d}$ & $9.22 \pm 0.01^{\mathrm{c}}$ & $4.33 \pm 0.01^{\mathrm{b}}$ & $2.21 \pm 0.10^{\mathrm{a}}$ \\
\hline & Ferulic acid & $22.95 \pm 0.04^{\mathrm{d}}$ & $9.46 \pm 0.04^{c}$ & $1.13 \pm 0.13^{\mathrm{a}}$ & $1.92 \pm 0.08^{\mathrm{b}}$ \\
\hline & Syringic acid & $8.53 \pm 0.04^{b}$ & $3.02 \pm 0.1^{\mathrm{a}}$ & n.d. & n.d. \\
\hline & Chlorogenic acid & $3.37 \pm 0.05^{\mathrm{c}}$ & $1.44 \pm 0.03^{b}$ & n.d. & $0.55 \pm 0.01^{\mathrm{a}}$ \\
\hline & Cinnamic acid & n.d. & n.d. & n.d. & n.d. \\
\hline & o-Coumaric acid & n.d. & n.d. & n.d. & n.d. \\
\hline & 3.4-Dimethoxycinnamic acid & n.d. & n.d. & n.d. & n.d. \\
\hline & Sinapic acid & n.d. & n.d. & n.d. & n.d. \\
\hline \multirow[t]{24}{*}{ Flavonoids } & Apigenin & $3.44 \pm 0.07^{\mathrm{d}}$ & $2.68 \pm 0.05^{\mathrm{c}}$ & $0.71 \pm 0.06^{\mathrm{a}}$ & $1.15 \pm 0.02^{\mathrm{b}}$ \\
\hline & Naringenin & $186.35 \pm 0.08^{d}$ & $130.67 \pm 0.01^{c}$ & $9.36 \pm 0.03^{b}$ & $4.82 \pm 0.06^{\mathrm{a}}$ \\
\hline & Luteolin & $2.58 \pm 0.07^{\mathrm{c}}$ & $2.34 \pm 0.03^{\mathrm{c}}$ & $1.88 \pm 0.05^{b}$ & $0.28 \pm 0.2^{\mathrm{a}}$ \\
\hline & Kaempferol & $2.46 \pm 0.04^{b}$ & $2.70 \pm 0.54^{b}$ & $0.99 \pm 0.05^{\mathrm{a}}$ & $1.41 \pm 0.06^{\mathrm{a}}$ \\
\hline & Epicatechin & $11.10 \pm 0.13^{\mathrm{a}}$ & n.d. & n.d. & n.d. \\
\hline & Chrysoeriol & $0.36 \pm 0.10^{b}$ & $0.34 \pm 0.02^{\mathrm{b}}$ & n.d. & $0.71 \pm 0.07^{\mathrm{a}}$ \\
\hline & Isorhamnetin & $8.19 \pm 0.09^{a}$ & $8.00 \pm 0.12^{\mathrm{a}}$ & $8.05 \pm 0.05^{\mathrm{a}}$ & $7.98 \pm 0.01^{\mathrm{a}}$ \\
\hline & Vitexin & $22.88 \pm 0.06^{\mathrm{c}}$ & $2.15 \pm 0.01^{b}$ & $0.22 \pm 0.01^{\mathrm{a}}$ & $0.33 \pm 0.03^{\mathrm{a}}$ \\
\hline & Apigenin-7-O- $\beta$-glucoside & $11.67 \pm 0.14^{\mathrm{d}}$ & $1.51 \pm 0.09^{c}$ & $0.49 \pm 0.07^{\mathrm{b}}$ & $0.34 \pm 0.11^{\mathrm{a}}$ \\
\hline & Luteolin-7-O- $\beta$-glucoside & $48.00 \pm 0.00^{\mathrm{b}}$ & $3.17 \pm 0.12^{\mathrm{a}}$ & n.d. & n.d. \\
\hline & Kaempherol-3-O-glucoside & $9.41 \pm 0.07^{c}$ & $1.62 \pm 0.24^{b}$ & $1.16 \pm 0.03^{\mathrm{b}}$ & $0.97 \pm 0.10^{\mathrm{a}}$ \\
\hline & Hyperoside & $10.17 \pm 0.90^{\mathrm{b}}$ & $1.32 \pm 1.28^{\mathrm{a}}$ & n.d. & n.d. \\
\hline & Quercetin-3-O-glucoside & $29.00 \pm 1.35^{\mathrm{b}}$ & $3.38 \pm 2.43^{\mathrm{a}}$ & n.d. & n.d. \\
\hline & Amentoflavone & $1.02 \pm 0.02^{\mathrm{b}}$ & $0.28 \pm 1.44^{\mathrm{a}}$ & $0.13 \pm 0.09^{\mathrm{a}}$ & n.d. \\
\hline & Apigenin & n.d. & n.d. & n.d. & $0.37 \pm 1.31^{\mathrm{a}}$ \\
\hline & Rutin & $284.63 \pm 1.07^{\mathrm{b}}$ & $28.30 \pm 0.08^{C}$ & n.d. & n.d. \\
\hline & Baicalein & n.d. & n.d. & n.d. & n.d. \\
\hline & Catechin & n.d. & n.d. & n.d. & n.d. \\
\hline & Quercetin & n.d. & n.d. & n.d. & n.d. \\
\hline & Myricetin & n.d. & n.d. & n.d. & n.d. \\
\hline & Baicalin & n.d. & n.d. & n.d. & n.d. \\
\hline & Quercitrin & n.d. & n.d. & n.d. & n.d. \\
\hline & Liquiritigenin & $1766.33 \pm 1.17^{\mathrm{c}}$ & $124.08 \pm 2.13^{b}$ & $13.10 \pm 0.07^{\mathrm{a}}$ & $12.40 \pm 0.09^{\mathrm{a}}$ \\
\hline & Isoliquiritigenin & $1013.02 \pm 1.93^{c}$ & $219.14 \pm 0.07^{\mathrm{b}}$ & $16.70 \pm 0.10^{\mathrm{a}}$ & $16.60 \pm 0.08^{\mathrm{a}}$ \\
\hline \multirow[t]{9}{*}{ Isoflavonoids } & Daidzein & $86.10 \pm 1.02^{\mathrm{b}}$ & $7.75 \pm 0.2^{\mathrm{a}}$ & n.d. & n.d. \\
\hline & Genistein & $577.01 \pm 5.2^{d}$ & $407.12 \pm 4.04^{c}$ & $364.34 \pm 7.30^{b}$ & $324.05 \pm 8.08^{a}$ \\
\hline & Formononetin & $1081.11 \pm 4.58^{c}$ & $112.24 \pm 5.03^{b}$ & $14.20 \pm 0.05^{\mathrm{a}}$ & $13.80 \pm 0.05^{\mathrm{a}}$ \\
\hline & Equol & n.d. & n.d. & n.d. & n.d. \\
\hline & Glicitein & $114.09 \pm 1.53^{c}$ & $13.20 \pm 0.05^{\mathrm{b}}$ & $0.52 \pm 0.02^{\mathrm{a}}$ & $0.21 \pm 0.06^{\mathrm{a}}$ \\
\hline & Calycosin & $337.54 \pm 2.34^{c}$ & $115.03 \pm 1.56^{b}$ & $11.30 \pm 1.01^{\mathrm{a}}$ & $11.02 \pm 0.09^{\mathrm{a}}$ \\
\hline & Biochanin A & $1013.02 \pm 2.51^{c}$ & $219.45 \pm 0.08^{b}$ & $16.70 \pm 0.07^{\mathrm{a}}$ & $16.60 \pm 0.10^{\mathrm{a}}$ \\
\hline & Daidzin & $324.25 \pm 3.00^{c}$ & $200.10 \pm 1.00^{b}$ & $17.20 \pm 1.05^{\mathrm{a}}$ & $15.60 \pm 0.75^{\mathrm{a}}$ \\
\hline & Glicitin & n.d. & n.d. & n.d & n.d. \\
\hline \multirow[t]{2}{*}{ Lignans } & Enterolacton & n.d. & n.d. & n.d. & n.d. \\
\hline & Pinoresinol & $120.15 \pm 0.05^{b}$ & $117.12 \pm 0.03^{b}$ & $53.01 \pm 0.02^{\mathrm{a}}$ & n.d. \\
\hline \multirow[t]{2}{*}{ Triterpenoids } & 18- $\beta$ Glycyrrhetic acid & $2049.05 \pm 1.17^{\mathrm{a}}$ & n.d. & n.d & n.d. \\
\hline & Glycyrrhizin & n.d. & n.d. & n.d. & n.d. \\
\hline \multirow[t]{3}{*}{ Coumarine } & Aesculetin & $1.230 .08^{\mathrm{b}}$ & $0.58 \pm 0.01^{a}$ & n.d. & n.d. \\
\hline & Scopoletin & $0.83 \pm 0.09^{c}$ & $0.38 \pm 0.01^{b}$ & n.d. & $0.12 \pm 0.07^{\mathrm{a}}$ \\
\hline & Umbelliferon & n.d. & n.d. & n.d. & n.d. \\
\hline
\end{tabular}

${ }^{\S}$ Values are means \pm SD of three measurements; a,b,c,d,e means in the same row not sharing the same superscript are significantly different (p $<0.01$ ); dw-dry weight.

Table 3

TPC and TFC.

\begin{tabular}{|c|c|c|c|c|}
\hline Extracts & L1 & L2 & $\mathbf{L 3}$ & L4 \\
\hline Total phenolics (mg GAE/g of dw) & $37.27 \pm 0.55^{\mathrm{a}}$ & $31 \pm 0.27^{\mathrm{b}}$ & $16.5 \pm 0.78^{\mathrm{c}}$ & $13.23 \pm 0.36^{\mathrm{d}}$ \\
\hline Total flavonoids (mg QE/g of dw) & $5.90 \pm 0.05^{\mathrm{a}}$ & $3.83 \pm 0.17^{b}$ & $3.68 \pm 0.23^{\mathrm{c}}$ & $2.69 \pm 0.11^{\mathrm{d}}$ \\
\hline
\end{tabular}

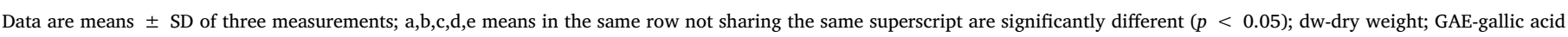
equivalent; QE- quercetin equivalents

and other bioactive compounds. Considering that, the number of identified and quantified compounds in fresh and dry root and leaf extracts of G. glabra from Fruska Gora, Serbia (L1-L4, respectively) has been expanded in the present work (Table 2).
The results indicate that the major bioactive compound in G. glabra extracts was 18- $\beta$ glycyrrhetic acid, detected only in the fresh licorice root extract, sample L1 $(2049.05 \mu \mathrm{g} / \mathrm{g})$. The presence of this compound was noticed before in most licorice extracts; it showed anticancer 
Table 4

Antioxidant potential of $G$. glabra extracts.

\begin{tabular}{|c|c|c|c|c|c|c|}
\hline & \multicolumn{4}{|l|}{ Extracts } & \multicolumn{2}{|l|}{ Standards } \\
\hline & L1 & L2 & L3 & L4 & BHA & BHT \\
\hline DPPH & $11.5 \pm 0.34^{c}$ & $46.17 \pm 0.53^{\mathrm{d}}$ & $58.93 \pm 0.7^{\mathrm{e}}$ & $206.52 \pm 0.60^{f}$ & $9.64 \pm 0.04^{\mathrm{b}}$ & $8.23 \pm 0.28^{\mathrm{a}}$ \\
\hline HO. & $315.27 \pm 0.17^{\mathrm{c}}$ & $415.79 \pm 0.04^{d}$ & $616.14 \pm 0.0^{\mathrm{e}}$ & $715.77 \pm 0.23^{f}$ & $117.17 \pm 0.03^{a}$ & $120.49 \pm 1.82^{\mathrm{b}}$ \\
\hline $\mathrm{O}_{2}^{\cdot-}$ & $37.23 \pm 0.10^{c}$ & $44.51 \pm 0.18^{d}$ & $48.87 \pm 0.5^{\mathrm{e}}$ & $84.33 \pm 0.16^{f}$ & $35.23 \pm 0.09^{b}$ & $23.55 \pm 0.18^{\mathrm{a}}$ \\
\hline NO. & $36.37 \pm 0.25^{c}$ & $57.46 \pm 0.3^{\mathrm{d}}$ & $502.72 \pm 0.0^{\mathrm{e}}$ & $775.2 \pm 0.65^{f}$ & $23.52 \pm 0.21^{\mathrm{a}}$ & $28.12 \pm 0.1^{\mathrm{b}}$ \\
\hline \multicolumn{7}{|c|}{$\begin{array}{l}\text { Reducing power (mg of ascorbic acid equivalents (AAE)/g of } \\
\quad \mathrm{dw} \text { ) }\end{array}$} \\
\hline FRAP & $55 \pm 1.20$ & $38,48 \pm 0.42$ & $5.17 \pm 0.9$ & $2.66 \pm 0.77$ & $107.18 \pm 0.30$ & $145.23 \pm 0.30$ \\
\hline
\end{tabular}

Data are means \pm SD of three measurements. a,b,c,d,e means in the same row not sharing the same superscript are significantly different $(p<0.05)$; dw-dry weight

\section{control}
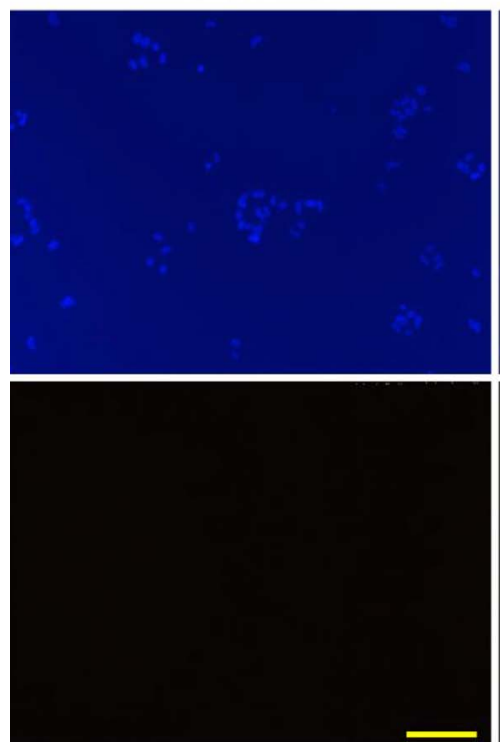

$10 \mu \mathrm{g} / \mathrm{ml}$
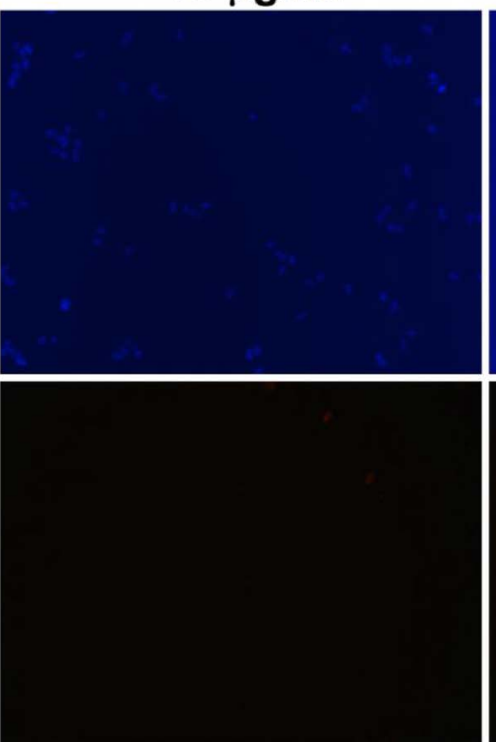

$30 \mu \mathrm{g} / \mathrm{ml}$

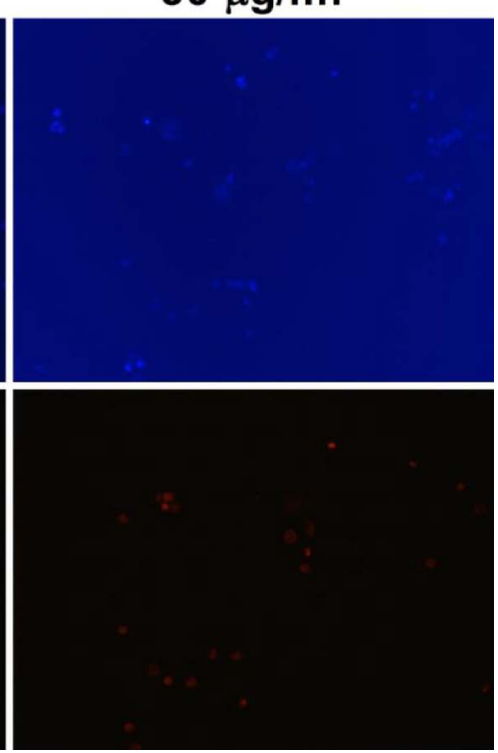

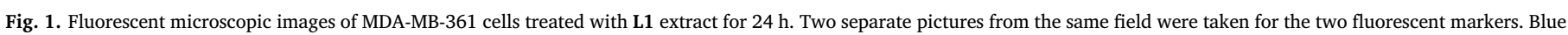

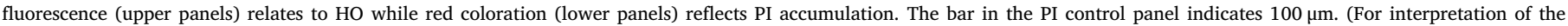
references to colour in this figure legend, the reader is referred to the web version of this article.)

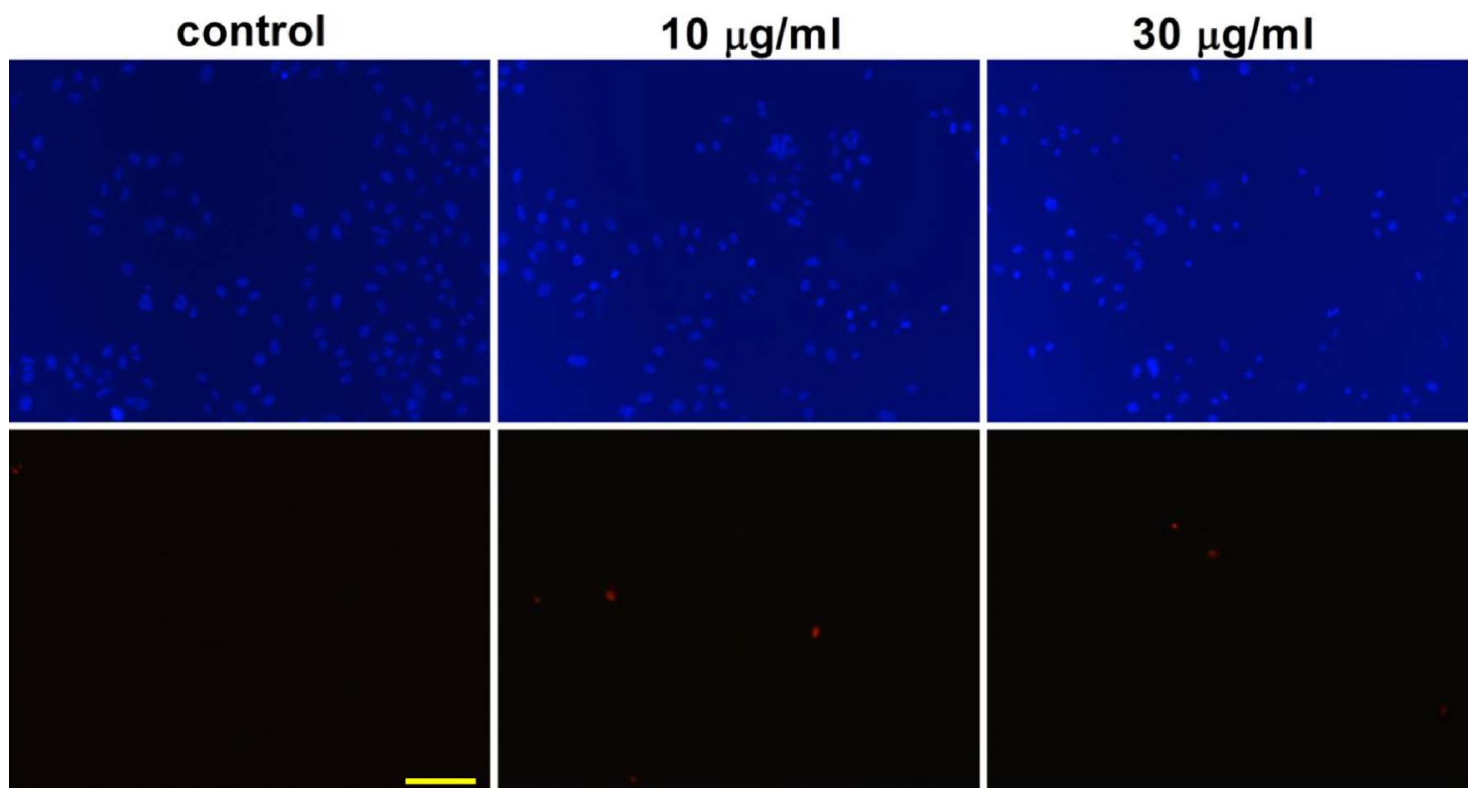

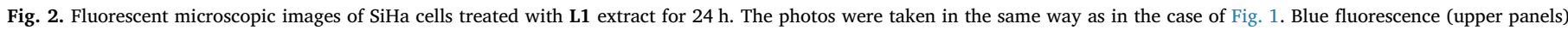

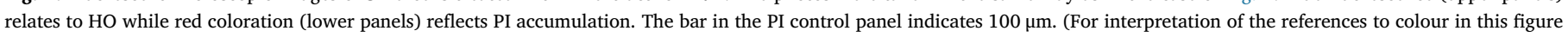
legend, the reader is referred to the web version of this article.) 


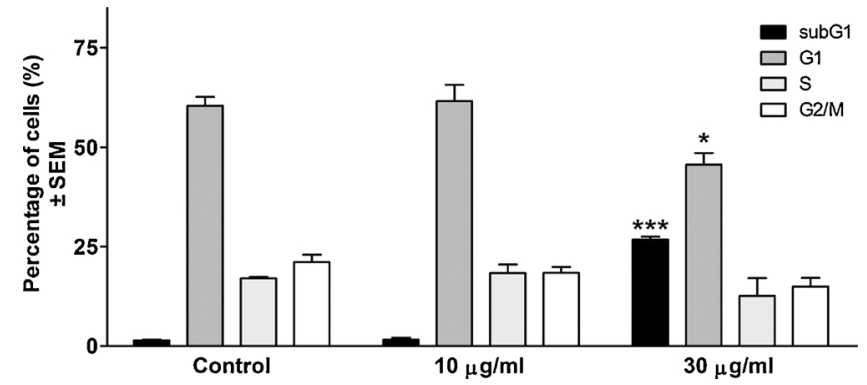

Fig. 3. The effect of $\mathbf{L} 1$ extract on the cell cycle distribution of SiHa cells after $24 \mathrm{~h}$ of incubation. * and *** indicate p $<0.05$ and $\mathrm{p}<0.001$ as compared with the control cells, respectively.

activity in several in vitro and in vivo cancer chemopreventive models (Wang and Yang, 2007; Yang et al., 2015). Other biologically active compounds that were detected and quantified in high amount belong to the class of phenolic compounds and acting as phytoestrogens. Flavonon liquiritigenin and chalcone-type flavonoid isoliquiritigenin are the most abundant flavonoids in licorice extracts. Liquiritigenin was found as highly selective agonist of $\beta$-estrogen receptor, while isoliquiritigenin has a potential as cancer chemopreventive agent (Cheel et al., 2010). The greatest level of these bioactive compounds was noticed in sample L1, namely extract of fresh licorice root $(1766.33 \mu \mathrm{g} / \mathrm{g}$ and $1013.02 \mu \mathrm{g} / \mathrm{g}$, respectively). Both isoliquiritigenin and liquiritigenin were identified in earlier studies of licorice originating from other regions, but the content of these compounds was lower than that in the present study (Liao et al., 2012a,b; Wang and Yang, 2007; Zhang and Ye, 2009; Zheng et al., 2014). The presence of the best-known health benefit flavonoids such as rutin, quercetin, lutein, naringenin, kaempherol-7- $O$-glucoside in licorice was detected in earlier reports, but was not quantified (Siracusa et al., 2011; Zhang and Ye, 2009). In this research these compounds were quantified in the root extract samples L1 and L2, in significantly higher amount than in leaf extract samples $\mathbf{L 3}$ and $\mathbf{L} 4$.

Further, isoflavonoids as a widespread and the most abundant group of phytoestrogens, play an important role in human nutrition due to their valuable health benefits. Presence of formononetin in licorice root was reported in earlier studies (Chin et al., 2007). The main isoflavonoids presented in the samples studied here were formononetin and biochanin A, followed by genistein. These compounds were noticed as dominant in fresh root of G. glabra, L1 (1081.11, 1013.54, $577.01 \mu \mathrm{g} / \mathrm{g} \mathrm{dw}$, respectively). O-methylated isoflavonoid calycosin and glucoside of daidzein, daidzin, were found in similar concentration and were also most abundant in the sample L1. These isoflavonoids were reported to possess primarily phytoestrogenic activity, but also antioxidant, anti-inflammatory and anticancer activity (Miadoková, 2009). They exert their anti-estrogen activity through binding to estrogen receptors $\alpha$ and $\beta$ (ER $\alpha$ and ER $\beta$ ) (Choi and Kim, 2014; Dixon, 2004; Dixon and Ferreira, 2002; Pilsková et al., 2010; Tang et al., 2010).

Phenolic acids were also observed in high level, where the antioxidant, quinic acid, found in the highest amount in the sample L1 $(730.89 \mu \mathrm{g} / \mathrm{g})$ followed by $p$-coumaric acid $(73.82 \mu \mathrm{g} / \mathrm{g})$ and $p$-hydroxybenzoic acid $(52.89 \mu \mathrm{g} / \mathrm{g})$. The rest phenolic acids were found in quite lower amount ranged from $0.35-22.95 \mu \mathrm{g} / \mathrm{g} \mathrm{dw}$.

Unlike the other detected compounds, the lignan pinoresinol, was observed in the extracts of fresh and dry root (53.01-120.15 $\mu \mathrm{g} / \mathrm{g}$ ) and fresh leaves in very similar concentration, which was not found in previous reports. Pinoresinol is recognized as strong anti-inflammatory agent in colon cell lines (During et al., 2012). It also affects the estrogen receptor in MCF-7 cells, that contribute to its estrogen activity (Hu et al., 2009).

Coumarines scopoletin and umbelliferon were detected in very low amount in all licorice extract samples. These results were in accordance with previous report (Cruz-Vega et al., 2009).

Based on the results presented in Table 2, it can be concluded that the most bioactive compounds, in the highest amounts, are found in the extract of G. glabra fresh root, L1. It could be explained by the fact that drying process can change bioactive compounds content and therefore biological activities of the extracts. Thus, drying of the plant material may lead to enzymatic degradation of secondary metabolites and this could result in the decrease of their content. The identified compounds could contribute prevention and treatment of many pathophysiological conditions. Previous studies indicated that only root of licorice contains a great content of bioactive compounds (Basar et al., 2015; Boonmuen et al., 2016; Cruz-Vega et al., 2009; Dai and Mumper, 2010; Khoddami et al., 2013; Martins et al., 2015; Zheng et al., 2014). In our study these compounds were identified and quantified also in fresh and dry leaves, though in much lower content. This part of plant could also be considered as a potential phytoremedy.

\subsection{TPC, TFC and antioxidant activity}

Phenolic compounds express antioxidant and/or radical scavenging ability, thanks to electron-donating phenol groups, stabilizing radical form. In the licorice extracts, we evaluated content of total phenolic compounds (TPC) and content of total flavonoid compounds (TFC) (Table 3). The greatest content of TPC in G. glabra extracts from Fruska Gora is noticed in the extract of the fresh root L1 $(37.27 \pm 0.55 \mathrm{mg}$ GA

Table 5

The antiproliferative action of the tested extracts.

\begin{tabular}{|c|c|c|c|c|c|}
\hline \multirow[t]{2}{*}{ Cell line } & \multirow[t]{2}{*}{ Conc. $(\mu \mathrm{g} / \mathrm{mL})$} & \multicolumn{4}{|c|}{ Growth inhibition (\%) \pm SEM } \\
\hline & & L1 & L2 & L3 & L4 \\
\hline \multirow[t]{2}{*}{ HeLa } & 10 & -* & - & - & - \\
\hline & 30 & $24.13 \pm 0.84$ & - & - & - \\
\hline \multirow[t]{2}{*}{$\mathrm{SiHa}$} & 10 & - & $22.96 \pm 2.67$ & - & - \\
\hline & 30 & $74.87 \pm 1.26$ & $39.54 \pm 1.82$ & - & $19.94 \pm 2.56$ \\
\hline \multirow[t]{2}{*}{ MCF7 } & 10 & - & - & - & - \\
\hline & 30 & $56.67 \pm 1.29$ & - & - & - \\
\hline \multirow[t]{2}{*}{ T47D } & 10 & $22.81 \pm 1.84$ & $13.61 \pm 2.04$ & - & $13.07 \pm 2.90$ \\
\hline & 30 & $54.35 \pm 1.03$ & $36.13 \pm 0.88$ & $19.18 \pm 2.97$ & $28.87 \pm 1.17$ \\
\hline \multirow[t]{2}{*}{ MDA-MB-231 } & 10 & - & - & - & $12.61 \pm 2.08$ \\
\hline & 30 & $64.26 \pm 1.77$ & $13.65 \pm 1.87$ & - & $13.80 \pm 2.74$ \\
\hline \multirow[t]{2}{*}{ MDA-MB-361 } & 10 & $15.42 \pm 1.66$ & - & - & - \\
\hline & 30 & $85.36 \pm 0.63$ & $14.17 \pm 2.78$ & $16.91 \pm 2.39$ & $14.01 \pm 2.80$ \\
\hline \multirow[t]{2}{*}{ A2780 } & 10 & - & - & - & - \\
\hline & 30 & $63.42 \pm 1.78$ & - & - & - \\
\hline
\end{tabular}

*: Extracts exhibiting growth inhibition lower that $10 \%$ are considered ineffective and their data are not given numerically for clarity. 
eq/g of $d w)$. The same extract was the richest in flavonoids as well $(5.90 \pm 0.05 \mathrm{mg} \mathrm{QE} \mathrm{eq} / \mathrm{g}$ of dw).

Some studies reported moderate to high capacity for neutralization of DPPH, NO, OH and $\mathrm{O}_{2} \cdot{ }^{-}$radicals of dry root extracts of G. glabra from different localities, compared to synthetic antioxidants (Saraf et al., 2013; Siracusa et al., 2011; Sultana et al., 2010; Visavadiya and Narasimhacharya, 2006). In order to determine antioxidant potential and/or scavenging capacity of G. glabra roots and leaves extracts under study, several tests were performed: $\mathrm{DPPH}, \mathrm{NO}, \mathrm{OH}$ and $\mathrm{O}_{2} \cdot{ }^{-}$and FRAP assay. The obtained results, are shown in Table 4. It can be noticed that the extracts of G. glabra roots (fresh and dry) exhibited markedly higher antioxidant potential than that of G. glabra leaves extracts. Antioxidant activity of tested samples was comparable with synthetic antioxidants such as butylated hydroxyanisole (BHA) and butylated hydroxytoluene (BHT). Extract of fresh G. glabra root (L1) showed the strongest scavenging capacity towards all radicals, while the most significant was the neutralization of DPPH radical (IC ${ }_{50}$ $11.50 \mu \mathrm{g} / \mathrm{mL})$ and $\mathrm{O}_{2} \cdot{ }^{-}\left(\mathrm{IC}_{50} 37.23 \pm 0.10 \mu \mathrm{g} / \mathrm{mL}\right)$ radicals, followed by, NO ( IC $_{50} 36.37 \pm 0.25 \mu \mathrm{g} / \mathrm{mL}$ ). The obtained results indicate that the root of G. glabra from Fruska Gora possesses strong antioxidative potential, thanks to its high content of phenolic compounds, and could be used as a great source of various antioxidants in reducing oxidative damage in human body.

\subsection{Antiproliferative activities of the tested extracts}

The antiproliferative action of the prepared extracts were determined by means of MTT assay on a panel of human adherent cell lines of gynecological origin, containing four breast (T47D, MCF7, MDA-MB-231 and MDA-MB-361), two cervical (HeLa and SiHa) and one ovarian cancer cell line (A2780). It was found that L1 fresh root licorice extract exhibited a substantial action ( $>50 \%$ growth inhibition) at $30 \mu \mathrm{g} / \mathrm{mL}$ against all of the treated cell lines, with exception of HeLa cells, while other extracts exerted a modest action or were ineffective (Table 4). Based on these data, $\mathbf{L 1}$ extract was selected for additional investigations in order to characterize its action on the treated cancer cells.

The pronounced cell growth inhibitory property of L1 extract against MDA-MB-361 and SiHa cells justified further in vitro investigations including morphological studies. Therefore, fluorescent staining with Hoechst 33258 (HO) and propidium iodide (PI) dyes was performed after $24 \mathrm{~h}$ of treatment in order to obtain data concerning the possible mode of the antiproliferative action (Figs. 1 and 2).

The nuclei of control MDA-MB-361 or SiHa cells were homogenously stained with HO dye, with no PI uptake, indicating no changes in chromatin as well as intact membrane function. On the other hand, after $24 \mathrm{~h}$ treatment of estrogen-receptor positive $(\mathrm{ER}+)$ human breast cancer MDA-MB-361 cell line with 10 or $30 \mu \mathrm{g} / \mathrm{mL}$ of the extract L1, a small number of the nuclei were more intensively stained by HO dye, indicating low rate of chromatin condensation and, accordingly, apoptosis in a low rate. Further, intensive PI uptake, evidenced by reddish fluorescence, especially with higher dose of the extract, is indicating the deterioration of the membrane function in treated MDAMB-361 cells, which is characteristic feature of necrosis or secondary necrosis. This finding can be explained by a high necrotic potential of the extract against this cell line (Fig. 1).

After the same treatment of SiHa cervical cancer cells with 10 or $30 \mu \mathrm{g} / \mathrm{mL}$ of the extract $\mathbf{L} \mathbf{1}$, a portion of the nuclei was more intensively stained, indicating the condensation of chromatin, especially in case of higher dose treatment (Fig. 2). Accordingly, conclusion is that the extract induced apoptosis of the treated cells. PI uptake was detected at very low level.

Since the presence of apoptosis is a crucial feature of almost all antiproliferative or cancer preventive substances, the proapoptotic property of the most effective extract (L1) has been confirmed by means of cell cycle analysis in SiHa cells after labeling the cellular DNA with PI
(Fig. 3). The licorice fresh root extract $\mathbf{L} 1$ after $24 \mathrm{~h}$ treatment of SiHa cervical cancer cells exerted no substantial effect at $10 \mu \mathrm{g} / \mathrm{mL}$. The treatment with a higher concentration $(30 \mu \mathrm{g} / \mathrm{mL})$ of $\mathbf{L 1}$ resulted in a substantial and significant increase of hypodiploid (subG1) population on the expense of cell in G1 phase. The accumulation of the subG1 population is generally considered as a consequence of apoptotic selfdecomposition and therefore a marker of the programmed cell death. Accordingly, these findings are in agreement and are confirming results from double staining test.

Based on presented results concerning cell lines tests, it can be summarized that fresh licorice root extract $\mathbf{L} 1$ has a pronounced antiproliferative action against a broad range of cancer cell lines of gynecological origin. Induction of apoptosis or necrosis was evidenced in different cell lines as a component of this growth inhibitory action, indicating that the plant extract could be considered as a potential source of novel anticancer lead molecules and/or agent for phytomedical treatment of malignances (Table 5).

\section{Conclusion}

Biological potential of this plant material, licorice from Fruska Gora mountain, is connected to and based on its phytochemical properties, especially concerning the most active licorice part - fresh root, rich in phenolic compounds liquiritigenin, isoliquiritigenin, biochanin $\mathrm{A}$, formononetin, quinic acid and others, and triterpenoid $18-\beta$ glycyrrhetic acid, all confirmed as biologically and pharmacologically active compounds. The obtained results indicate that fresh root of the plant could be considered as potentialphytoremedy, specially very useful in treatment of problems and diseases of female reproductive tissues.

\section{Conflict of interest}

The authors declare that they have no conflict of interest.

\section{Acknowledgements}

This work was supported by the Ministry of Science and Environmental Protection of the Republic of Serbia (Project No. 172058) and Hungarian Scientific Research Fund (OTKA K109293).

\section{References}

Asha, M.K., Debraj, D., Prashanth, D., Edwin, J.R., Srikanth, H.S., Muruganantham, N., Dethe, S.M., Anirban, B., Jaya, B., Deepak, M., Agarwal, A., 2013. In vitro antiHelicobacter pylori activity of a flavonoid rich extract of Glycyrrhiza glabra and its probable mechanisms of action. J. Ethnopharmacol. 145, 581-586. http://dx.doi. org/10.1016/j.jep.2012.11.033.

Basar, N., Oridupa, O.A., Ritchie, K.J., Nahar, L., Osman, N.M.M., Stafford, A., Kushiev, H., Kan, A., Sarker, S.D., 2015. Comparative cytotoxicity of Glycyrrhiza glabra roots from different geographical origins against immortal human keratinocyte (HaCaT). Lung Adenocarcinoma (A549) and Liver Carcinoma (HepG2) Cells 948, 944-948.

Biondi, D.M., Rocco, C., Ruberto, G., 2005. Dihydrostilbene derivatives from glycyrrhiza glabra leaves. J. Nat. Prod. 59, 1099-1102.

Boonmuen, N., Gong, P., Ali, Z., Chittiboyina, A.G., Khan, I., Doerge, D.R., Helferich, W.G., Carlson, K.E., Martin, T., Piyachaturawat, P., Katzenellenbogen, J.A., Katzenellenbogen, B.S., 2016. Licorice root components in dietary supplements are selective estrogen receptor modulators with a spectrum of estrogenic and anti-estrogenic activities. Steroids 105, 42-49. http://dx.doi.org/10.1016/j.steroids.2015. 11.006.

Cheel, J., Antwerpen, P., Van Tumova, L., Onofre, G., Vokurkova, D., Zouaoui-Boudjeltia, K., Vanhaeverbeek, M., Neve, J., 2010. Free radical-scavenging, antioxidant and immunostimulating effects of a licorice infusion (Glycyrrhiza glabra L.). Food Chem. 122, 508-517. http://dx.doi.org/10.1016/j.foodchem.2010.02.060.

Cheesman, H., BeaBiocvis, A., Eserbauer, H., 1998. Hydroxyl-radical-induced-iron-catalysed degration of 2-deoxyribose. Biohem. J. 2, 649-653.

Chin, Y.W., Jung, H.A., Liu, Y., Su, B.N., Castoro, J.A., Keller, W.J., Pereira, M.A., Kinghorn, A.D., 2007. Anti-oxidant constituents of the roots and stolons of licorice (Glycyrrhiza glabra). J. Agric. Food Chem. 55, 4691-4697. http://dx.doi.org/10. 1021/jf0703553.

Choi, E.J., Kim, G.H., 2014. The antioxidant activity of daidzein metabolites, O-desmethylangolensin and equol, in HepG2 cells. Mol. Med. Rep. 9, 328-332. http://dx. doi.org/10.3892/mmr.2013.1752.

Cos, P., Ying, L., Callome, M., Hu, P., Cimanga, K., Van Poel, B., Pieters, L., Vlietinick, J., 
Van den Berghe, D., 1998. Structure-activity relationship and classification of flavonoids as inhibitors of Xanthine oxidase and superoxide scavengers. J. Nat. Prod. 61, $71-76$.

Cruz-Vega, D., Verde-Star, M.J., Salinas-Gonzalez, N.R., Rosales-Hernandez, B., EstradaGarcia, I., Mendez-Aragon, P., Carranza-Rosales, P., Gonzalez-Garza, M., CastroGarza, J., 2009. Review of pharmacological effects of Glycyrrhiza radix and its bioactive compounds. Zhongguo Zhong Yao Za Zhi 22, 557-559. http://dx.doi.org/ $10.1002 /$ ptr.

Dai, J., Mumper, R.J., 2010. Plant phenolics: extraction, analysis and their antioxidant and anticancer properties. Molecules 15, 7313-7352. http://dx.doi.org/10.3390/ molecules15107313.

Dixon, R.A., Ferreira, D., 2002. Genistein. Phytochemistry 60, 205-211. http://dx.doi. org/10.1016/S0031-9422(02)00116-4.

Dixon, R.A., 2004. Phytoestrogens. Annu. Rev. Plant Biol. 55, 225-261. http://dx.doi. org/10.1146/annurev.arplant.55.031903.141729.

Dong, Y., Zhao, M., Zhao, T., Feng, M., Chen, H., Zhuang, M., Lin, L., 2014. Bioactive profiles, antioxidant activities, nitrite scavenging capacities and protective effects on H2O2 injured PC12Cells of Glycyrrhiza glabra L. Leaf Root Extracts 9101-9113. http://dx.doi.org/10.3390/molecules19079101.

Dunlap, T.L., Wang, S., Simmler, C., Chen, S.N., Pauli, G.F., Dietz, B.M., Bolton, J.L., 2015. Differential effects of Glycyrrhiza species on genotoxic estrogen metabolism: licochalcone a downregulates P450 1B1, whereas isoliquiritigenin stimulates it. Chem. Res. Toxicol. 28, 1584-1594. http://dx.doi.org/10.1021/acs.chemrestox. 5 b00157.

During, A., Debouche, C., Raas, T., Larondelle, Y., 2012. Among Plant Lignans, Pinoresinol Has the Strongest Antiinflammatory Properties in Human Intestinal Caco2Cells. http://dx.doi.org/10.3945/jn.112.162453.

Farag, M.A., Porzel, A., Wessjohann, L.A., 2015. Unequivocal glycyrrhizin isomer determination and comparative in vitro bioactivities of root extracts in four Glycyrrhiza species. J. Adv. Res. 6, 99-104. http://dx.doi.org/10.1016/j.jare.2014.05.001.

Flamini, G., Tebano, M., Luigi, P., Ceccarini, L., Simone, A., Longo, I., 2007. Comparison between the conventional method of extraction of essential oil of Laurus nobilis L. and a novel method which uses microwaves applied in situ without resorting to an oven. J. Chromatogr. A 1143, 36-40. http://dx.doi.org/10.1016/j.chroma.2007.01. 031.

Fukai, T., Satoh, K., Nomura, T., Sakagami, H., 2003. Preliminary evaluation of antinephritis and radical scavenging activities of glabridin from Glycyrrhiza glabra. Fitoterapia 74, 624-629. http://dx.doi.org/10.1016/S0367-326X(03)00164-3.

Fukumoto, L.R., Mazza, G., 2000. Assessing antioxidant and prooxidant activities of phenolic compounds. J. Agric. Food Chem. 48, 3597-3604. http://dx.doi.org/10 1021/jf000220w.

Green, C., Wagner, A., Glogowski, J., Skipper, I., Wishnok, S., Tannenbaum, R., 1982. Analysis of nitrat, nitrit and $\left[{ }^{15} \mathrm{~N}\right]$ nitrit in biological fluids. Anal Biochem. 126, $131-138$.

Gupta, V.K., Fatima, A., Faridi, U., Negi, A.S., Shanker, K., Kumar, J.K., Rahuja, N., Luqman, S., Sisodia, B.S., Saikia, D., Darokar, M.P., Khanuja, S.P.S., 2008. Antimicrobial potential of Glycyrrhiza glabra roots. J. Ethnopharmacol. 116, 377-380. http://dx.doi.org/10.1016/j.jep.2007.11.037.

Hu, C., Liu, H., Du, J., Mo, B., Qi, H., Wang, X., Ye, S., Li, Z., 2009. Estrogenic activities of extracts of Chinese licorice (Glycyrrhiza uralensis) root in MCF-7 breast cancer cells. J. Steroid Biochem. Mol. Biol. 113, 209-216. http://dx.doi.org/10.1016/j.jsbmb.2008. 12.019 .

Huang, R., Chu, Y., Huang, Q., Chen, X., Jiang, Z., Zhang, X., 2014. 18 b -Glycyrrhetinic acid suppresses cell proliferation through inhibiting thromboxane synthase in nonsmall cell. Lung Cancer 9, 1-9. http://dx.doi.org/10.1371/journal.pone.0093690.

Jia, Z., Tang, M., Wu, J., 1999. The determination of flavonoids content in mulberry and their scavenging effects on superoxide radicals. Food Chem. 64, 555-559.

Jiang, J., Zhang, X., True, A.D., Zhou, L., Xiong, Y.L., 2013. Inhibition of lipid oxidation and rancidity in precooked pork patties by radical-scavenging licorice (Glycyrrhiza glabra) extract. J. Food Sci. 78. http://dx.doi.org/10.1111/1750-3841.12273.

Khoddami, A., Wilkes, M.A., Roberts, T.H., 2013. Techniques for analysis of plant phenolic compounds. Molecules 18, 2328-2375. http://dx.doi.org/10.3390/ molecules18022328.

Liao, W.C., Lin, Y., Chang, T., Huang, W., 2012a. Identification of two licorice species, Glycyrrhiza uralensis and Glycyrrhiza glabra, based on separation and identification of their bioactive components. Food Chem. 132, 2188-2193. http://dx.doi.org/10. 1016/j.foodchem.2011.12.051.

Liao, W.C., Lin, Y.H., Chang, T.M., Huang, W.Y., 2012b. Identification of two licorice species, Glycyrrhiza uralensis and Glycyrrhiza glabra, based on separation and identification of their bioactive components. Food Chem. 132, 2188-2193. http://dx doi.org/10.1016/j.foodchem.2011.12.051.

Martins, N., Barros, L., Dueñas, M., Santos-Buelga, C., Ferreira, I.C.F.R., 2015. Characterization of phenolic compounds and antioxidant properties of Glycyrrhiza glabra L. rhizomes and roots. RSC Adv. 5, 26991-26997. http://dx.doi.org/10.1039/
C5RA03963K.

Miadoková, E., 2009. Isoflavonoids - an overview of their biological activities and potential health benefits. Interdiscip. Toxicol. 2, 211-218. http://dx.doi.org/10.2478/ v10102-009-0021-3.

Mosmann, T., 1983. Rapid colorimetric assay for cellular growth and survival: application to proliferation and cytotoxicity assays. J. Immunol. Methods 65, 55-63. http://dx. doi.org/10.1016/0022-1759(83)90303-4.

Orčić, D., Francišković, M., Bekvalac, K., Svirčev, E., Beara, I., Lesjak, M., Mimica-Dukić, N., 2014. Quantitative determination of plant phenolics in Urtica dioica extracts by high-performance liquid chromatography coupled with tandem mass spectrometric detection. Food Chem. 143, 48-53. http://dx.doi.org/10.1016/j.foodchem.2013.07. 097.

Parvaiz, M., Hussain, K., Khalid, S., Hussnain, N., Iram, N., Hussain, Z., Ali, M.A., 2014. A review: medicinal importance of Glycyrrhiza glabra L. (Fabaceae family). Glob. J. Pharmacol. 8, 8-13. http://dx.doi.org/10.5829/idosi.gjp.2014.8.1.81179.

Pilsková, L., Riecanský, I., Jagla, F., 2010. The physiological actions of isoflavone phytoestrogens. Physiol. Res. 59, 651-664 (931902 [pii]).

Ribble, D., Goldstein, N.B., Norris, D.A., Shellman, Y.G., 2005. A simple technique for quantifying apoptosis in 96-well plates. BMC Biotechnol. 5, 12. http://dx.doi.org/10. $1186 / 1472-6750-5-12$

Sánchez-Moreno, C.A., Larrauri, J., Saura-Calixto, F., 1999. Free radical scavenging capacity and inhibition of lipid oxidation of wines, grape juices and related polyphenolic constituents. Food Res. Int. 32, 407-412. http://dx.doi.org/10.1016/S09639969(99)00097-6.

Saraf, B.D., Inam, F., Deo, S.S., 2013. Antimicrobial and Antioxidant Activities of Methanol Extract Roots of.

Simmler, C., Pauli, G.F., Chen, S.N., 2013. Phytochemistry and biological properties of glabridin. Fitoterapia 90, 160-184. http://dx.doi.org/10.1016/j.fitote.2013.07.003.

Siracusa, L., Saija, A., Cristani, M., Cimino, F., D’Arrigo, M., Trombetta, D., Rao, F., Ruberto, G., 2011. Phytocomplexes from liquorice (Glycyrrhiza glabra L.) leaves chemical characterization and evaluation of their antioxidant, anti-genotoxic and anti-inflammatory activity. Fitoterapia 82, 546-556. http://dx.doi.org/10.1016/j. fitote.2011.01.009.

Sultana, S., Haque, A., Hamid, K., Urmi, K., Roy, S., 2010. Antimicrobial, cytotoxic and antioxidant activity of methanolic extract of Glycyrrhiza glabra. Agric. Biol. J. North Am. 1, 957-960. http://dx.doi.org/10.5251/abjna.2010.1.5.957.960.

Tang, J.Y., Li, S., Li, Z.H., Zhang, Z.J., Hu, G., Cheang, L.C.V., Alex, D., Hoi, M.P.M., Kwan, Y.W., Chan, S.W., Leung, G.P.H., Lee, S.M.Y., 2010. Calycosin promotes angiogenesis involving estrogen receptor and mitogen-activated protein kinase (MAPK) signaling pathway in zebrafish and HUVEC. PLoS One 5. http://dx.doi.org/10.1371/ journal.pone.0011822.

Tang, Z., Li, T., Tong, Y., Chen, X., Chen, X., Wang, Y., Lu, J., Angeles, L., 2015. A systematic review of the anticancer properties of compounds isolated from licorice (Gancao). Planta Med. 1670-1687.

Vermes, I., Haanen, C., Reutelingsperger, C., 2000. Flow cytometry of apoptotic cell death. J. Immunol. Methods 243, 167-190. http://dx.doi.org/10.1016/S0022 1759(00)00233-7.

Visavadiya, N.P., Narasimhacharya, A.V.R.L., 2006. Hypocholesterolaemic and antioxidant effects of Glycyrrhiza glabra (Linn) in rats. Mol. Nutr. Food Res. 1080-1086. http://dx.doi.org/10.1002/mnfr.200600063.

Vlaisavljevic, S., Kaurinovic, B., Popovic, M., Vasiljevic, S., 2016. Profile of Phenolic Compounds in Trifolium pratense L. extracts at different growth stages and their biological activities. Int. J. Food Prop. http://dx.doi.org/10.1080/10942912.2016. 1273235.

Wang, Y., Yang, Y., 2007. Simultaneous quantification of flavonoids and triterpenoids in licorice using HPLC. J. Chromatogr. B Analyt. Technol. Biomed. Life Sci. 850, 392-399. http://dx.doi.org/10.1016/j.jchromb.2006.12.032.

Wang, L., Yang, R., Yuan, B., Liu, Y., Liu, C., 2015. The antiviral and antimicrobial activities of licorice, a widely-used Chinese herb. Acta Pharm. Sin. B 5, 310-315. http://dx.doi.org/10.1016/j.apsb.2015.05.005.

Yan, T., Lin, S., Ho, C., Leung, L.K., 2014. Chemico-Biological Interactions The licorice flavonoid isoliquiritigenin reduces DNA-binding activity of AhR in MCF-7 cells. Chem. Biol. Interact. 221, 70-76. http://dx.doi.org/10.1016/j.cbi.2014.07.015.

Yang, R., Wang, L.Q., Yuan, B.C., Liu, Y., 2015. The pharmacological activities of licorice. Planta Med. 81, 1654-1669. http://dx.doi.org/10.1055/s-0035-1557893.

Zadeh, J.B., Kor, Z.M., 2013. Licorice (Glycyrrhiza Glabra Linn) As a Valuable Medicinal Plant 1. pp. 1281-1288.

Zhang, Q., Ye, M., 2009. Chemical analysis of the Chinese herbal medicine Gan-Cao (licorice). J. Chromatogr. A. http://dx.doi.org/10.1016/j.chroma.2008.07.072.

Zheng, H., Li, Y., Wang, Y., Zhao, H., Zhang, J., Chai, H., Tang, T., Yue, J., Guo, A.M., Yang, J., 2014. Downregulation of COX-2 and CYP 4A signaling by isoliquiritigenin inhibits human breast cancer metastasis through preventing anoikis resistance, migration and invasion. Toxicol. Appl. Pharmacol. 280, 10-20. http://dx.doi.org/10. 1016/j.taap.2014.07.018. 